\title{
Self-Bias and Gender-Bias in Student Peer Evaluation: AN EXPANDED STUDY
}

\author{
Peter M. Ostafichuk and Jim Sibley \\ University of British Columbia \\ ostafichuk@mech.ubc.ca
}

\begin{abstract}
This paper expands on two studies first presented in 2015 in which gender-based differences in peer evaluation and the self-bias of students in engineering design courses were considered. In the current study, 50 evaluation events across 12 cohorts in four different courses, from first to third year at the University of British Columbia (UBC) are considered. Self evaluations and peer evaluations are used to measure how students rank their own contributions to the team relative to how they rank their teammates' contributions. In addition, this study examines potential gender-bias when students evaluate peers, focusing on differences in evaluation score given to like- and different-gender individuals

The study confirms the presence of significant gender bias when evaluating others. Consistently across the contexts considered, both male and female students tend to evaluate female students more favourably. This study also confirms the presence of a self-bias-the tendency to rate one's own contributions more favourably than peers' contributions-that grows as a course progresses. In both forms of bias, statistically significant effects due to the course, team size and composition, the timing of evaluations, and various other interaction effects are observed. Overall, gender biases and self biases of $5 \%$ are shown to be common, and biases at times exceeding $10 \%$ are also observed. This has implications when considering the validity and reliability of peer and self evaluation as a summative assessment tool. This work suggests care should be taken in the use of self and peer evaluation data, as well as in team formation, since that appears to impact biases. One favourable outcome from this work seems to be the observation that peer and self evaluation biases diminish in later years, as students have more teamwork and evaluation experience.
\end{abstract}

Keywords: peer evaluation, teamwork, self evaluation, gender-bias, self-bias, self-serving bias

\footnotetext{
${ }^{1}$ A binary definition for gender is used throughout this study for two reasons. First, student information at UBC is available to instructors only in a binary form. Second, surveys of our student population suggest fewer
}

\section{INTRODUCTION}

The ability to work in a team is a necessity in engineering. Effective teamwork involves a suite of related skills, the development of which are widely recognized and required by accrediting bodies (e.g. [1]). One element of effective teamwork is the ability to evaluate the contributions of team members (both self and peer) to the team goals. A well-designed peer evaluation process can improve the student experience and lead to more powerful learning outcomes. As with any assessment, validity (do the assessments measure what the intend to) and reliability (are the assessments consistent) are core aspects of effective self and peer evaluation. Incorporating self and peer evaluation within teamwork in a course has an added benefit of being authentic - the team members are the ones best positioned to assess contributions of their teammates, and evaluations are done in context, not in an artificial scenario, such as an exam or essay.

Regarding reliability and validity of self and peer evaluation, there is no absolute measure to compare against. Other than perhaps having an independent expert observer embedded in each team through all interactions, there is no way to know for certain that evaluations are accurate. That said, it is possible to test to see if reliability and validity are not met. Namely, consistency in evaluations of an individual is expected, with any variations statistically averaging out such that no consistent bias between different groups in a class would be detected.

In two previous studies conducted in 2015 , different forms of bias were identified in peer evaluation. The first study [2] suggested gender-based ${ }^{1}$ differences may be present in peer evaluation scores received, but this was not found to be statistically significant without also considering effects of personality type. The second study [3] revealed several intriguing results in terms of selfserving bias - measured based on the difference between than $0.5 \%$ of students self-identify with non-binary gender; while it would be invaluable to include non-binary gender identity in this study, there would not be enough statistical power to draw conclusions. 
self evaluation and peer evaluation scores-that increased with time during the course. In addition, a statistically significant difference in the self-serving bias between male and female students was observed early in the course, but this diminished as the course progressed.

Both studies were limited to one particular second-year mechanical engineering design course at UBC (MECH 223). The gender-bias study considered three cohorts (i.e. three years), while the self-bias study considered a single cohort. While the findings from both studies were intriguing, it is possible the observed effects were unique to the particular cohorts or course context considered. The primary motivation of the current study is to attempt to confirm the findings from the 2015 studies across a broader range of contexts. In total, the current work considers twelve cohorts across four different team-based engineering courses, from first to third year. Additional background on peer evaluation and self-bias is provided in the following sub-sections.

\subsection{Peer evaluation}

Peer evaluation can be used to foster a better team experience and to equitably recognize individual student's contributions to their team's success.[4] There are two common form of peer evaluation: formative and summative. Formative peer evaluation (not for marks) is used to encourage positive teaming behaviours and reform or decrease poor behaviors. Summative peer evaluations (for marks) are used to temper group grades, to ensure that students get what they deserve-highly performing students that contribute well to their team are rewarded and students that do not contribute do not benefit from the often higher group grades. When we design peer evaluations we often include different amounts of summative and formative elements, depending on the timing in the life cycle of the team [5] and the ultimate purpose of the evaluation. It can be challenging to design peer evaluation schemes that are valid, reliable, and at the same time feasible to implement.[6],[7]

Two commonly used peer evaluation instruments include allocation of points (AoP) and behaviorally anchored rating scales (BARS) approaches.[10] AoP, sometimes called "single score," is a zero-sum method that requires evaluators to divide a set number of points between their teammates.[8],[9] If some teammates are to receive above-average scores, at least one other teammate must receive a below-average score. This ensures that the average score each evaluator gives their teammates is the same across the class, and the average score received by all students across the class is also the same. The scores are usually accompanied by written comments. Evaluatees typically receive their aggregate score and/or comments in an anonymous, randomly-ordered fashion at the end of the evaluation period, end of the course, or not at all. The behaviorally anchored rating scales (BARS) approach uses an evaluation rubric with predefined criteria and descriptors (anchors) for different levels of performance in those criteria.[10] This focuses the evaluation on specific factors important for team success, it helps communicate constructive team behaviors to students, and aims to reduce subjectivity and improve inter-rater reliability.[10],[11], [12]. Enszer and Castellanos showed that the two approaches have a statistically significant positive correlation.[13]

Still, in spite of our best efforts to design fair peer evaluation schemes, some bias may still exist. In a metaanalysis of leaders and managers, Eagly et al. showed men's leadership and agentic behavior were evaluated more favorably compared to those of women;[14] effects of role congruity were suggested as the source of prejudice towards female leaders.[15] Harsh reported a gender bias amongst 290 senior undergraduates in business in which evaluators tended to give higher evaluations, both in terms of performance and leadership, to managers of the same gender;[16] females received higher overall evaluations than males, in contrast to the findings of Eagly. In peer evaluations, Ruble showed the presence of same-gender bias, with greater bias in peer evaluations conducted using an AoP approach in comparison to a non-zero-sum approach.[17] Finally, in the two previous studies that form the basis of this paper, gender was found to influence peer and self evaluations.[2],[3]

\subsection{Self-Bias}

Self-efficacy refers to an individual's confidence in successfully completing a given set of tasks.[18] Selfefficacy can have a positive effect for individuals, as it correlates to work-related performance.[19] Self-serving attribution bias (or simply self-serving bias) occurs when an individual attributes success to one's own actions, and attributes failures to the actions of others.[20] This effect can be especially pronounced in groups with established leader-member dynamics, as there is an obvious target for blame.[21] These effects can also be reversed depending on one's attribution style; most commonly either optimistic or pessimistic. Optimistic refers to attributing success to internal and stable factors (i.e. self), and failures to external and unstable factors (i.e. others), where pessimistic refers to attributing success to external factors, and failures to internal factors.[22] Self-efficacy, performance, and selfserving attribution bias are all interrelated, as self-serving attributions increase self-efficacy which further enhances performance.[23]

\section{COURSE CONTEXT}

The current study considers four different courses, each spanning multiple years. The course details and the use of peer evaluation within the courses is described below. 


\subsection{Courses Considered}

The courses and cohorts considered in this current study are shown below in Table 1. The number of female and male students are shown in each case, along with the number of evaluations (jointly self and peer in all cases) conducted in that course.

Table 1: Courses Considered

\begin{tabular}{|c|c|c|c|c|c|}
\hline \multirow[t]{2}{*}{ Course } & \multirow[t]{2}{*}{ Title } & \multirow[t]{2}{*}{ Cohort } & \multicolumn{2}{|c|}{ Students } & \multirow[t]{2}{*}{ Evals } \\
\hline & & & $\mathbf{F}$ & $\mathbf{M}$ & \\
\hline \multirow{3}{*}{ APSC 100} & \multirow{3}{*}{$\begin{array}{l}\text { Introduction to } \\
\text { Engineering I }\end{array}$} & 2016 & 231 & 557 & 3 \\
\hline & & 2017 & 218 & 631 & 2 \\
\hline & & 2018 & 275 & 613 & 4 \\
\hline \multirow[t]{2}{*}{ APSC 101} & \multirow{2}{*}{$\begin{array}{l}\text { Introduction to } \\
\text { Engineering II }\end{array}$} & 2017 & 222 & 519 & 3 \\
\hline & & 2018 & 203 & 609 & 3 \\
\hline \multirow[t]{4}{*}{ MECH 223} & \multirow{4}{*}{$\begin{array}{l}\text { Introduction to } \\
\text { Mechanical } \\
\text { Design }\end{array}$} & 2015 & 28 & 93 & 7 \\
\hline & & 2016 & 34 & 92 & 7 \\
\hline & & 2017 & 26 & 101 & 7 \\
\hline & & 2018 & 35 & 95 & 7 \\
\hline \multirow[t]{3}{*}{ MECH 326} & \multirow{3}{*}{$\begin{array}{l}\text { Mechanical } \\
\text { Design I }\end{array}$} & 2016 & 29 & 106 & 3 \\
\hline & & 2017 & 27 & 86 & 3 \\
\hline & & 2018 & 34 & 110 & 1 \\
\hline
\end{tabular}

All courses have a large team component, with the same teams maintained for the entire course duration. All courses also have team activities in class (including regular team quizzes), and major team deliverables in the form of projects or design assignments. The APSC 100 course is 3 -credits and is taken by all first year engineering students at UBC. It covers topics of design, decision-making, prototyping, ethics, and the engineering profession. APSC 101 is a follow-up 3-credit course taken by approximately $90 \%$ of the students in APSC 100, and done in the following term. It focuses on design, sustainability, risk, and simulation. MECH 223 is a 7-credit second year mechanical engineering design course, with emphasis on the design process, additional design tools beyond those introduced in the first year courses, and content specific to mechanical engineering. This course is only taken by students in mechanical engineering, representing approximately $15 \%$ of the first year engineering cohort. Finally, MECH 326 is a third year mechanical engineering design course, focusing on topics related to machine design, including fatigue, fracture, shaft design, weld design, and finite element analysis. It is taken by approximately three-quarters of third year mechanical engineering students, and approximately 60 students from engineering physics. Each course in the sequence from APSC 100 to MECH 326 represents a progression to more complex and more technical content.

\subsection{Use of Peer Evaluation in the Courses}

In all four courses considered, iPeer (ipeer.ctlt.ubc.ca), an online peer evaluation integrated with our LMS, was used with a modified BARS approach, described further below. Peer evaluations were used in a mixed formative/summative manner, with all evaluations considered in the final grade but also with regular feedback to individuals to help recognize successes and highlight team functioning issues early. Each team member evaluated each other teammate as well as themselves, although the self evaluations were formative only and did not count towards grades.

As noted in Table 1, typically 3 to 7 evaluations were performed in each course. The evaluation criteria varied only slightly between courses, and typically included the following (quality of work was introduced to the rubric in 2018):

- Class and tutorial contributions: to what degree did the teammate contribute to team quizzes, studio worksheets, in-class discussions, and other courserelated tasks?

- Project contributions: to what degree did the teammate assume responsibility for their work and participate equitably in the project?

- Quality of work: to what degree did the quality of the teammate's work meet overall team expectations?

- Communication: to what degree did the teammate communicate effectively and constructively with other team members, in and out of class?

- Equity: to what degree did the teammate contribute to creating a positive and inclusive team environment?

- Professionalism: to what degree did the teammate act with professional behaviour and communication etiquette?

Five levels of mastery were used, ranging in score from 0 to 4 . Each criterion had a unique descriptor at each level of mastery, but the general categorization was as follows:

- Unacceptable (0): Took away from team's ability to perform in the criterion

- Emerging (1): Showed some effort, but created an impediment for the team to grow in the criterion

- Marginally acceptable (2): Provided minimum contribution expected in the criterion; may have created an annoyance for the team in the criterion

- Accomplished (3): Performed individually at a high level in the criterion

- Exemplary (4): Performed individually at a high level and helped other teammates to also perform at a high level in the criterion

In all courses, criteria were equally weighted, leading to a raw score of 20 or 24 (depending on whether 5 or 6 criteria were used). Each evaluator's scores given to teammates (not including their self-evaluation) were normalized to an average of 100 . With this system, differences in evaluation standards between individuals are removed; similarly, individuals do not penalize themselves by giving their teammates high evaluations, nor do they 
benefit by giving their teammates low evaluations. This also ensures fairness between teams in that each team has an average peer evaluation score of 100 . Consequently, the benefits of the AoP peer evaluation approach were incorporated into the modified BARS approach.

A lateness penalty of $2 \%$ per day late, up to one week (-14\% maximum) was applied to overdue evaluations in each course. This penalty is not included in the analysis of this study; only raw normalized scores are used. The final peer evaluation score for each individual in each course is the average they receive from their teammates across all evaluations. The team contribution to each individual's course grade is determined by multiplying the team grade by the individual's average peer evaluation score.

\section{STATISTICAL METHODS}

The 12 courses and 50 evaluations in this study were analyzed through IBM SPSS Statistics 25. All data were combined to a single data set with each evaluator-evaluatee pair for a given evaluation event represented as a separate entry (16,698 entries in total). Multiple evaluations by the same evaluator during a course were not treated as repeat measures since (as will be demonstrated) biases in evaluations changed during a course and across years. Data were analyzed using the Generalized Linear Model in SPSS. The requirement of equal variances required for univariate (ANOVA) and multivariate (MANOVA) analyses in SPSS were not met (Levene's Test failed at a significance $<0.001$ ), and the multifactor model developed prevented the use of a Games-Howell (or similar) post-hoc test in SPSS to confirm significance of findings with ANOVA/MANOVA.

Two main dependent variables were considered in the analysis:

- F-M bias: defined as the difference between the average peer evaluation score an individual gave all of their female teammates to the average they gave male teammates. This applies to a single evaluation event. A positive F-M bias value indicates the individual tends to give female teammates higher peer evaluation scores than male teammates. This variable is undefined all-male teams (there were no all-female teams).

- Self bias: defined as the difference between the self evaluation score an individual gives themselves compared to the average peer evaluation score they give all other teammates. A positive value in self bias indicates the individual rates their contribution to their team above the average they give the rest of their teammates in that evaluation event.

For the F-M Bias analysis, a total of five predictor variables were considered in SPSS:

- Gender of evaluator (female or male)
- Team composition (more females than males, parity, more males than females)

- Timing of evaluation (first half of course, second half of course, end of course)

- Course (APSC 100, APSC 101, MECH 223, $\mathrm{MECH}$ 326)

- $\quad$ Team size $(4,5,6$, or 7 students $)$

Starting with the five variables and all two-way interactions (15 effects total), the model was refined in SPSS by dropping effects, one at a time, that showed significance greater than 0.05 . The final model for F-M Bias consisted of three main effects and two interaction effects (noted by the product of effects in the last two rows), as shown in Table 2 .

Table 2: F-M Bias Effects Model

\begin{tabular}{|lccc|}
\hline Effect & $\begin{array}{c}\text { Degrees of } \\
\text { freedom }\end{array}$ & $\begin{array}{c}\text { Wald Chi- } \\
\text { Square }\end{array}$ & Sig. \\
\hline Gender & 1 & 10.2 & 0.001 \\
\hline Course & 3 & 98.1 & $<0.001$ \\
\hline Team size & 3 & 29.4 & $<0.001$ \\
\hline Gender ${ }^{*}$ timing & 4 & 11.2 & 0.024 \\
\hline Gender $^{*}$ composition & 4 & 16.2 & 0.003 \\
\hline
\end{tabular}

For the Self Bias model, a better fit was found when the team composition predictor variable was replaced with the count of the number of female students on the team. Otherwise, the same approach was used as with F-M Bias and the resulting model had five main effects and no interaction effects, as shown in Table 3.

Table 3: Self Bias Effects Model

\begin{tabular}{|lccc|}
\hline Effect & $\begin{array}{c}\text { Degrees of } \\
\text { freedom }\end{array}$ & Wald Chi-Square & Sig. \\
\hline Gender & 1 & 5.6 & 0.008 \\
\hline Course & 3 & 417.9 & $<0.001$ \\
\hline Team size & 4 & 33.7 & $<0.001$ \\
\hline Timing & 2 & 11.1 & 0.026 \\
\hline Female count & 6 & 45.4 & 0.002 \\
\hline
\end{tabular}

\section{RESULTS AND DISCUSSION}

For both the F-M Bias and the Self Bias analyses, the Wald Chi-Square value shown in Table 2 and Table 3 indicates how strong an influence that effect has in the describing the variation in the dependent variable (higher value indicates stronger influence). As shown in both cases, course and team size are the dominant effects, with the number of females on a team also having a strong influence in the self bias observed. Detailed results are presented in the subsections below. In all charts, values shown with "**" were different from 0 with statistical significance of better than $p=0.01$; values with "*”" were different from zero to a significance level of better than 0.05. Both F-M Bias and Self Bias are reported in terms of 
the normalized scores; thus a positive F-M Bias of 5 would correspond to a females receiving a $5 \%$ higher peer evaluation score, while a Self Bias of -5 would correspond to an individual giving themselves a self evaluation 5\% lower than the average peer evaluation they gave.

\subsection{Influence of Course on F-M Bias}

Figure 1 shows the mean F-M Bias by course in terms of female evaluators, male evaluators, and all evaluators. The difference (female minus male) is also shown.

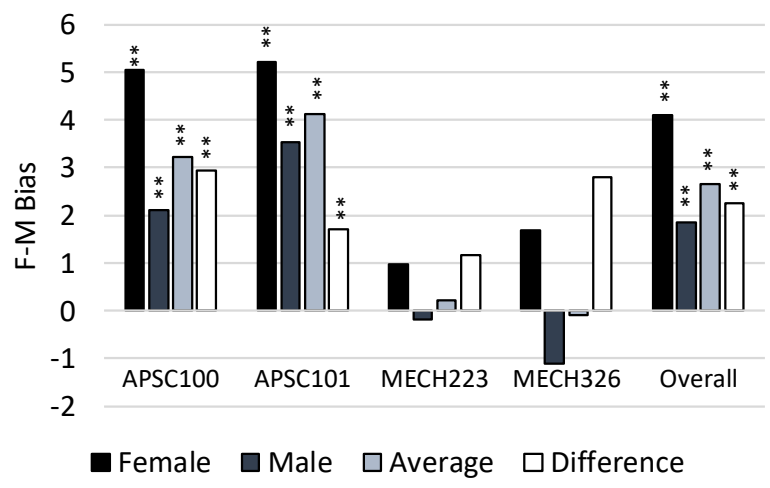

Fig. 1: F-M Bias by Course

Several important observations from the above chart include the following:

- Overall, both male and female students tend to give female students higher evaluations by almost 3\% (given by the "Average" "Overall" bar). This in itself is not equivalent to a bias, as one explanation could be that female students may be contributing more towards team function and success on average, and therefore may be earning the higher evaluations.

- Female students on average give other female students evaluations more than $2 \%$ higher than male students give female students (given by the "Difference" "Overall" bar). This does suggest a bias in that a valid and reliable peer evaluation should be independent of the evaluator's gender. This bias may be on the part of the female evaluators, the male evaluators, or both.

- There is a strong course (or perhaps year) dependence in terms of the overall F-M Bias. The bias was strongest in first year (3-4\%), and it almost disappeared by third year $(<0.1 \%)$.

\subsection{Influence of Evaluation Timing on F-M Bias}

The data comparing the time an evaluation was conducted in a course versus the F-M Bias are shown in Fig. 2. As indicated by the lack of timing as a main effect in the model (Table 2), there were no statistically significant differences between adjacent evaluations (early-mid or mid-late) for either female or male students; however, statistically significant differences between female and male students were noted at each evaluation period. What this result shows is that the observed F-M Bias tends to persist from the beginning to the end of a course.

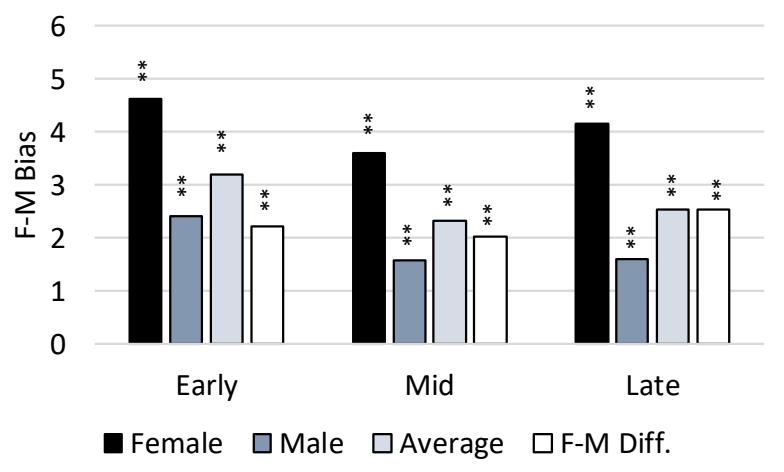

Fig. 2: F-M Bias by Timing

\subsection{Influence of Team Composition on F-M Bias}

The influence of whether there are more females, more males, or parity on a team is shown in Fig. 3. The F-M Bias is highest (for both male and female students) when the team is dominated by female students. The differences between teams with more female members and the others were statistically significant (to better than a level of 0.05 ), but there was no statistical significance in differences between parity and majority-male teams. In addition, the F-M Bias in itself was statistically significant to a level of 0.01 or better for females, males, and on average in each case, with the exception of males and parity, which was significant to better than 0.05 . The difference between female and males was significant only for male-dominated teams $(p=0.001)$, but it should be noted there are few evaluations with teams at parity $(13.9 \%$ of total) or with females in the majority $(3.6 \%)$.

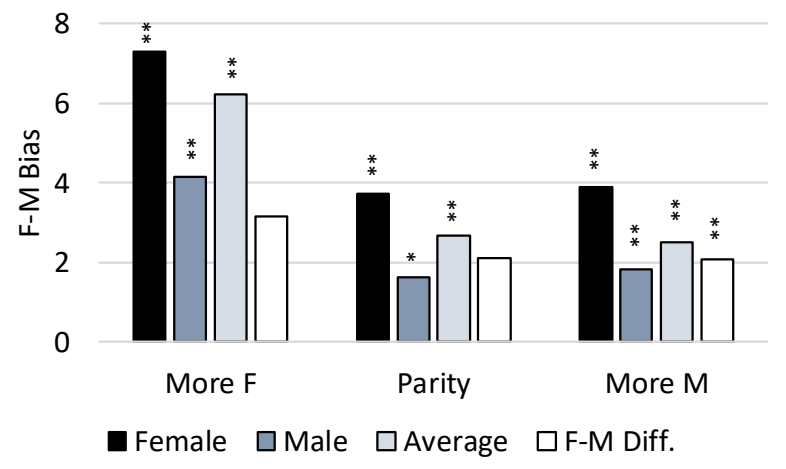

Fig. 3: F-M Bias by Team Composition 


\subsection{Influence of Team Size on F-M Bias}

The final comparison for F-M Bias is for team size (see Fig. 4). Male student's evaluations in terms of F-M Bias differed only slightly based on team size (and not significantly), but females on teams of 4 students showed a large F-M Bias (>10\%). The F-M Bias for female students was significantly different from 0 at all team sizes; male F-M Bias was only significant at teams of 6 or 7 .

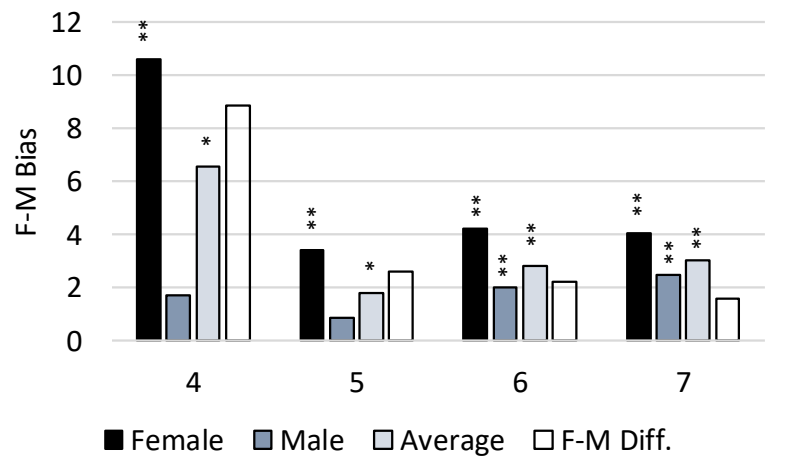

Fig. 4: F-M Bias by Team Size

\subsection{Influence of Gender on Self Bias}

As was observed in the 2015 study, this study also revealed a tendency for students to exhibit a positive self bias (meaning that they evaluated their own contributions more favorably than the contributions of their teammates). Gender had a statistically significant effect overall on self bias. Female students had an average self bias of $8.28 \%$ (i.e. they rated themselves higher than their peers by this amount), while male students had an average self bias of $7.8 \%$. Both of these findings were statistically different from 0 , and a statistically significant difference $(p<0.001)$ between females and males was noted. Additional effects of the course, evaluation timing, and team composition are described in the following sub-sections.

\subsection{Influence of Course on Self Bias}

Statistically significant differences between self bias were found by course, as shown in Fig. 5. As given in Table 3, this effect did not include an interaction with gender. Based on the female, male, and average columns, this finding was statistically significant in three of the courses. Unlike the 2015 study, across all courses, years, and evaluations in this study, no significant difference in self bias based on gender was found, except in MECH 326.

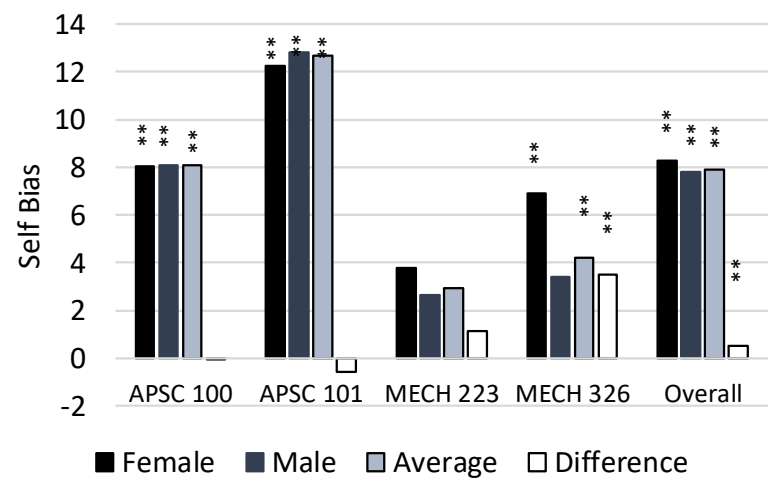

Fig. 5: Self Bias by Course

\subsection{Influence of Evaluation Timing on Self Bias}

Similar to the 2015 study observations, self bias was found to increase during a course. Differences between consecutive evaluations were statistically significant to better than 0.01 for male, female, and average evaluations (but not for the difference between male and female), as shown in Fig. 6.

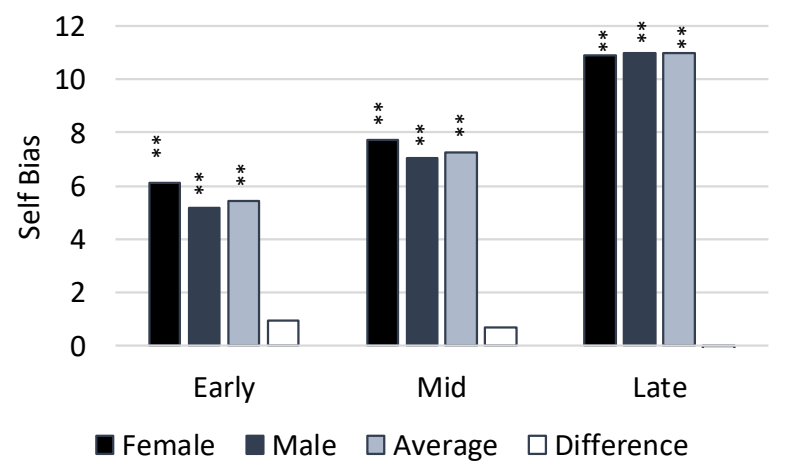

Fig. 6: Self Bias by Timing

\subsection{Influence of Team Composition on Self Bias}

Lastly, considering the number of female members on a team, there was a statistically significant difference between female and male students' self bias when there were either three or four females on a team (see Fig. 7). Interestingly, four females on a team corresponds to a male minority, and in this case (and only this case) male students tended to show a greater self bias than female students - in other cases, as noted previously, female students showed the greater self bias. 


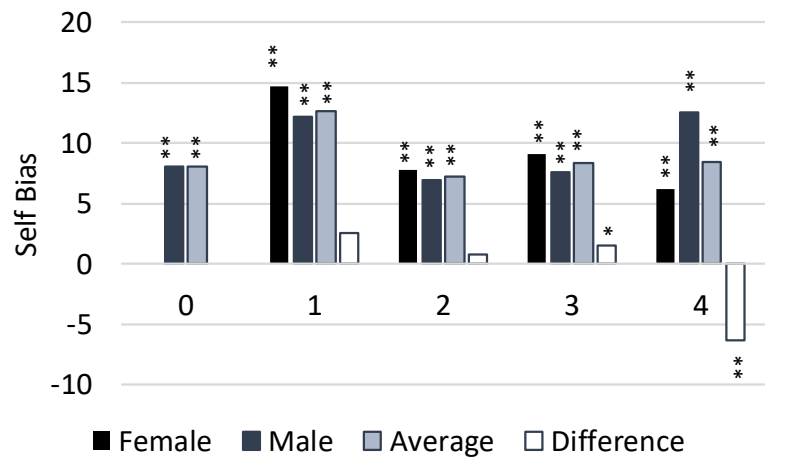

Fig. 7: Self Bias by Number of Females on Team

\section{CONCLUSIONS}

This expanded study has helped to clarify findings from the two previous studies conducted in 2015. It has revealed that a significant bias exists for male and female students when evaluating each other. In addition, the existence of a self bias (rating oneself more favorably than rating one's peers) is common across different courses and years. As found previously, this self bias tends to increase as a course progresses, at least when students are working with the same teammates as they did an all courses considered here.

This expanded study has revealed several other important observations. In particular, both gender bias and self bias are influenced by the team gender composition and size. The overall gender bias and self bias tended to decrease as students progressed through these courses. This may be due to increasing familiarity with self and peer evaluation, changes in student attitude or competency with team work or peer evaluation, differences in course context and topics, or other factors not considered here.

Overall, this work has implications in terms of the use of self and peer evaluation. For an educator, it is important to recognize that gender biases may influence peer evaluation scores by $5 \%$ or even $10 \%$. This should be of concern when considering the validity and reliability of peer evaluation instruments if used for summative evaluation. This study also showed the presence of a significant self bias (ranging from about $5 \%$ at the beginning of a course to $10 \%$ at the end). If used for summative evaluation, it suggests evaluations should not be conducted solely at the end of a course (when self bias is greatest). In terms of team formation, gender parity showed the best results in terms of low gender bias and low self bias.

Several limitations of this work and areas for future investigation include considering at other mechanisms for peer evaluation beyond iPeer, as well as the rubric used with these courses. In addition, each evaluation was treated as an independent measurement; although, as described, repeat measures are likely not the correct way to model the evaluations considered in this study, consideration of multiple evaluations by the same person should be explored more systematically. Finally, all evaluations consider involved formative and summative elements, with scores and comments (anonymously) revealed to evaluatees. It is possible the formative/summative balance, and/or releasing or not releasing evaluation results to students, may influence bias.

\section{References}

[1] Canadian Engineering Accreditation Board, "Questionnaire for Evaluation of an Engineering Program," Ottawa.

[2] Ostafichuk, P.M., d'Entremont, A., Shirzad, N., and Sibley, J., "Gender and Personality Type Influence in Peer Evaluation," in Proc. of ASEE 2015 Conf. (Seattle, WA, June 15-17, 2015), 14 pp., 2015.

[3] Ostafichuk, P.M., Mattucci, S., d'Entremont, A., Shirzad, N., and C. Naylor, "Self-perception differences based on gender and personality type in team projects," in Proc. Of CEEA 2015 Conf. (Hamilton, ON, May 31-June 3, 2015), 7 pp., 2015.

[4] Millis, B.J. and P.G.Cottell, Cooperative Learning for Higher Education Faculty, Oryx Press, (1998).

[5] Delson, N.J., "Increasing team motivation in engineering design courses," International Journal of Engineering Education 17(4-5): 359-66 (2001).

[6] Baker, D.F. "Peer Assessment in Small Groups: A Comparison of Methods." Journal of Management Education, Vol. 32, No. 2, 183-209 (2008).

[7] Saavedra, R. and S.K. Kwun, "Peer evaluation in selfmanaging work groups." Journal of Applied Psychology, Vol. 78, 450-462 (1993).

[8] Fellenz, M. R., 2006, "Toward fairness in assessing student groupwork: A protocol for peer evaluation of individual contributions," Journal of Management Education, Vol. 30, pp. 570-591.

[9] Gueldenzoph, L. E., May, G. L., 2002, "Collaborative peer evaluation: Best practices for group member assessments." Business Communication Quarterly, Vol. 65, pp. 9-20.

[10] Smith, P. C. and L.M. Kendall, "Retranslation of expectations: An approach to the construction of unambiguous anchors for rating scales," Journal of Applied Psychology, 47: 149-155 (1963).

[11] MacDonald, H.A., L.M. Sulsky, "Rating Formats and Rater Training Redux: A Context Specific Approach for Enhancing the Effectiveness of Performance Management," Canadian Journal of Behavioural Science, Vol. 41, No. 4, 227-240 (2009). 
[12] Ohland, M.W., R.A. Layton, M.L. Loughry, and A.G. Yuhasz, "Effects of Behavioral Anchors on Peer Evaluation Reliability." Journal of Engineering Education, Vol. 94, No. 3., 319-326 (2005).

[13] Enszer, J.A., M. Castellanos, "A Comparison of Peer Evaluation Methods in Capstone Design," Proc. ASEE Annual Meeting, Atlanta, GA, June, 2013.

[14] Eagly, A.H., S.J. Karau, and M.G. Makhijani, "Gender and the Effectiveness of Leaders: A Meta-Analysis," Psychological Bulletin, Vol. 117, No. 1, 125-145 (1995).

[15] Eagly, A.H., and S.J. Karau, "Role Congruity Theory of Prejudice Toward Female Leaders," Psychological Review, Vol. 109, No. 3, 573-598 (2002).

[16] Harsh, K.L., "Gender Differences in Evaluation of Performance and Leadership Ability: Autocratic vs. Democratic Managers," Sex Roles, Vol. 35, Nos. 5/6, 337-361 (1996).

[17] Ruble, T.L., S.A. Hernandez, and W.J. Amadio, "A Comparison of Peer Evaluation Systems in Team-Based Learning," Proc. of the Academy of Business Education Annual Conference. 2004.
[18] Bandura, A. "Self-efficacy mechanism in human agency." American Psychologist, Vol. 37, 122-147 (1982).

[19] Stajkovic, A.D., and F. Luthans. "Self-efficacy and work related performance: a meta-analysis." Pschological Bulletin, Vol. 124(2), 240-261, (1998).

[20] Zuckerman, M. "Attribution of success and failure revisited, or the motivational bias is alive and well in attribution theory." Journal of Personality, Vol. 47, 245287, (1979).

[21] Martinko, M.M., P. Harvey, and S.C. Douglas. "The role, function, and contribution of attribution theory to leadership: A review." The Leadership Quarterly, Vol. 18, 561-585, (2007).

[22] Abramson, L.Y., M.E.P. Seligman, and J.D. Teasdale. "Learned helplessness in humans: Critique and reformulation." Journal of Abnormal Psychology, Vol. 87, 49-74, (1978).

[23] Silver, W.S., T.R. Mitchell, and M.E. Gist. "Responses to successful and unsuccessful performance: The moderating effect of self-efficacy on the relationship between performance and attributions." Organizational Behavior and Human Decision Processes, Vol. 62, 286299, (1995). 